REVIEW ARTICLE

\title{
Parasite infection and host group size: a meta-analytical review
}

\author{
JESSE E. H. PATTERSON* and KATHREEN E. RUCKSTUHL \\ Department of Biological Sciences, University of Calgary, 2500 University Drive NW, Calgary, Alberta T2N1N4, Canada
}

(Received 5 November 2012; revised 9 December 2012; accepted 13 December 2012; first published online 21 February 2013)

SUMMARY

\begin{abstract}
Many studies have identified various host behavioural and ecological traits that are associated with parasite infection, including host gregariousness. By use of meta-analyses, we investigated to what degree parasite prevalence, intensity and species richness are correlated with group size in gregarious species. We predicted that larger groups would have more parasites and higher parasite species richness. We analysed a total of 70 correlations on parasite prevalence, intensity and species richness across different host group sizes. Parasite intensity and prevalence both increased positively with group size, as expected. No significant relationships were found between host group size and parasite species richness, suggesting that larger groups do not harbour more rare or novel parasite species than smaller groups. We further predicted that the mobility of the host (mobile, sedentary) and the mode of parasite transmission (direct, indirect, mobile) would be important predictors of the effects of group sizes on parasite infection. It was found that group size was positively correlated with the prevalence and intensity of directly and indirectly transmitted parasites. However, a negative relationship was observed between group size and mobile parasite intensity, with larger groups having lower parasite intensities. Further, intensities of parasites did not increase with group size of mobile hosts, suggesting that host mobility may negate parasite infection risk. The implications for the evolution and maintenance of sociality in host species are discussed, and future research directions are highlighted.
\end{abstract}

Key words: gregarious, group size, meta-analysis, parasite infection, parasite transmission, parasitism, species richness, sociality.

\section{INTRODUCTION}

By definition, parasites impose costs on their hosts and are partially responsible for shaping the phenotype, genotype, and life-history traits of host organisms. In many host species, the more heavily parasitized individuals are less likely to mate (Hamilton and Zuk, 1982), more likely to raise inferior offspring if they do mate (Neuhaus, 2003), suffer from reduced life expectancy (Walter and Proctor, 1999) and display modified behaviours (Poulin, 1992). Parasites can impose major costs on their hosts and thus influence many aspects of host physiology, ecology, life history and behaviour. Parasites have been found to affect various parameters of host social organization, such as group size (reviewed by Côté and Poulin, 1995 and Altizer et al. 2003), sexual segregation (Ferrari et al. 2010), dominance hierarchies (Ezenwa, 2004) and contact networks (van Baalen, 2002). Parasite transmission rates typically scale positively with the density of the

* Corresponding author: Department of Biological Sciences, University of Calgary, 2500 University Drive NW, Calgary, Alberta T2N1N4, Canada. E-mail: jesse. patterson@ucalgary.ca host population (density-dependent transmission) or with the frequency of interactions between the host and the parasite's infective stage (frequencydependent transmission). As such, host behavioural and ecological traits that increase host proximity to infective stages and local population size/density, such as social group size, should increase parasite infection intensity (number of parasites per individual host; Bush et al. 1997), parasite prevalence (the presence or absence of a parasite species on or in an individual host; Bush et al. 1997) and parasite species richness (the number of parasites on or in a host individual, population or species; Bush et al. 1997). The combination of these 3 terms will generally be referred to herein as 'parasite infection'.

Host sociality (gregariousness) is a widespread phenomenon spanning many taxa including insects, fish, birds and mammals. Sociality has been the topic of much empirical and theoretical research concerning both ultimate and proximate causes for its existence. In essence, for gregariousness to have evolved and to have remained evolutionarily stable, the benefits of forming groups must consistently outweigh the costs. All social species experience both costs and benefits of living in groups. The benefits

Parasitology (2013), 140, 803-813. C Cambridge University Press 2013. The online version of this article is published within an Open Access environment subject to the conditions of the Creative Commons Attribution-NonCommercial-ShareAlike licence < http:// creativecommons.org/licenses/by-nc-sa/3.0/>. The written permission of Cambridge University Press must be obtained for commercial re-use. doi:10.1017/S0031182012002259 
accrued to individuals living in groups are plentiful and variable and may include predator avoidance (i.e. dilution effects; Ostfeld and Keesing, 2000), increased foraging efficiency, improved thermoregulation and mate choice (Krause and Ruxton, 2002). Alexander (1974) noted that there are no automatic or universal benefits gained by individuals through group formation, but there are automatic and universal costs, including, but not limited to, increased intra-specific competition for limited resources, predator attraction and an increased probability of misdirecting parental care (Krause and Ruxton, 2002). When the costs are exceedingly large, group formation may be discouraged altogether. Given that most parasite transmission is either density-dependent or frequency-dependent, epidemiological models predict host density and local population size as key contributing factors controlling the transmission dynamics of infectious diseases because these variables often set the threshold for successful parasite invasion and spread (Anderson and May, 1978). Increased parasite infection is widely interpreted as a cost of gregariousness (Côté and Poulin, 1995). The magnitude of the cost depends on the degree to which infection negatively affects host fitness.

Alexander (1974) proposed that group formation and increased group size should lead to enhanced parasite infection among group members through increased transmission. Hoogland and Sherman (1976) and Freeland (1977) were the first researchers to empirically test Alexander's idea. Hoogland and Sherman addressed this question with contagious parasites (fleas) of colonial bank swallows (Riparia riparia) and Freeland examined this question with mobile, biting flies in primate (Cercocebus albigena, Cercopithecus ascanius, Piliocolobus badius) social groups. Hoogland and Sherman (1976) found a significant relationship between group size and both flea prevalence and intensity, lending support for Alexander's (1974) hypothesis. Freeland's data, on the other hand, did not support Alexander's hypothesis. Freeland found evidence of a dilution effect: group size increased when attacks from biting flies increased, suggesting that grouping may be beneficial in terms of reducing per capita attack rates. Further testing of effects of group size on parasite intensity and prevalence has corroborated these original findings. For instance, Kunz (1976) observed that bat fly (Trichobius corynorhini) intensities and group sizes of Townsend's big-eared bats (Corynorhinus townsendii) were positively correlated. Similar to Freeland (1977), Rubenstein and Hohmann (1989) found that dipteran biting fly intensities were negatively correlated with group size in feral horses (Equus caballus). The feral horses also appeared to form more tightly clustered aggregations when flies were more abundant, active or bothersome, suggesting a behavioural adaptation for dealing with dipteran parasitism (Rubenstein and Hohmann, 1989). This select cross-section of studies highlights the importance of understanding basic host and parasite biology when developing hypotheses and interpreting results with respect to the interplay between parasite infection and host gregariousness.

The risk of parasitism by contagious contacttransmitted parasites (i.e. parasites whose infective stages are directly transmitted via contact between hosts and are immediately infective - most ectoparasites; herein referred to as direct transmission) is predicted to positively correlate with group size as host proximity and the number and duration of conspecific contacts increases. A contagious parasite in which the infective stages occur off of the definitive host (i.e. in an intermediate host) and which are not immediately infective (i.e. most endoparasites; herein referred to as indirect transmission) should follow the same patterns as directly transmitted parasites if host groups are sedentary and exposure to infective stages is consistent. Host species that are highly mobile and range more widely are not predicted to acquire more indirectly transmitted infective stages in larger groups because such groups are able to move away from contaminated areas into more parasite-free environments (Côté and Poulin, 1995), thereby reducing group-member-to-group-member transmission of infective stages. However, this need not always be the case. For instance, if large mobile groups of predators forage more efficiently on certain prey species than smaller groups, and prey species are the intermediate hosts, then variation in predator group size may control the variation in the transmission rate of parasites. However, in general, the parasite infection intensity in mobile groups is predicted to show weak or absent correlations with group size. Mobile parasites (i.e. biting flies, mosquitoes, aquatic crustaceans) represent an interesting case: once a parasite has detected a group of hosts, the dilution effect predicts that as group size increases the probability that each group member has of being attacked decreases, resulting in an expected inverse relationship between group size and parasite intensity. However, mobile parasites can track their hosts' movement patterns, so host mobility is not expected to affect the relationship between mobile parasites and their hosts.

In earlier meta-analyses on this topic, Côté and Poulin (1995) and Rifkin et al. (2012) have generally supported the existence of an association between parasite infection and group size. These metaanalyses have both found, for instance, that contagious parasite infections increase with group size; however, Rifkin et al. (2012) did not support Côté and Poulin's (1995) finding that mobile parasite intensity decreased with increasing group size. Rifkin et al. (2012) did not explore the effects of host mobility, but Côté and Poulin (1995) did not find any correlations between either parasite intensity or 
Table 1. Studies on the relationship between host group size and parasite prevalence included in the meta-analyses

(Presented here, with number of groups examined $(n)$, the correlation coefficient $(r)$, host mobility $(\mathrm{M}=$ mobile, $\mathrm{S}=$ sedentary $)$, transmission mode $(\mathrm{I}=$ indirect, $\mathrm{D}=$ direct, $\mathrm{M}=$ mobile $))$

\begin{tabular}{|c|c|c|c|c|c|}
\hline Host/parasite system & Study & $\begin{array}{l}\text { Host } \\
\text { mobility }\end{array}$ & $\begin{array}{l}\text { Transmission } \\
\text { mode }\end{array}$ & $n$ & $r$ \\
\hline Swallows/arbovirus-swallow bug & Brown et al. (2001) & $\mathrm{S}$ & $\mathrm{D}$ & 17 & $0 \cdot 52$ \\
\hline Aphid/fungus & Cappuccino (1988) & $\mathrm{S}$ & $\mathrm{D}$ & 30 & $0 \cdot 47$ \\
\hline Grant's gazelle/strongyle & Ezenwa (2004) & M & I & 15 & $0 \cdot 1$ \\
\hline Impala/strongyle & Ezenwa (2004) & M & I & 15 & $0 \cdot 1$ \\
\hline Grant's gazelle/coccidia & Ezenwa (2004) & M & I & 15 & $0 \cdot 141$ \\
\hline Impala/coccidia & Ezenwa (2004) & M & I & 15 & $0 \cdot 141$ \\
\hline Eland/strongyle & Ezenwa (2004) & M & I & 15 & $0 \cdot 224$ \\
\hline Buffalo/strongyle & Ezenwa (2004) & M & I & 15 & $0 \cdot 374$ \\
\hline Hartebeest/strongyle & Ezenwa (2004) & M & I & 15 & $0 \cdot 447$ \\
\hline Thomson's gazelle/coccidia & Ezenwa (2004) & M & I & 15 & $0 \cdot 624$ \\
\hline Eland/coccidia & Ezenwa (2004) & M & I & 15 & $0 \cdot 624$ \\
\hline Hartebeest/coccidia & Ezenwa (2004) & M & I & 15 & $0 \cdot 819$ \\
\hline Buffalo/coccidia & Ezenwa (2004) & M & I & 15 & $0 \cdot 843$ \\
\hline Swallow/flea & Hoogland and Sherman (1976) & $\mathrm{S}$ & $\mathrm{D}$ & 22 & $0 \cdot 53$ \\
\hline Swallow/swallow bug & Møller (1987) & $\mathrm{S}$ & $\mathrm{D}$ & 32 & $0 \cdot 87$ \\
\hline Stickleback/copepod & Poulin (1999) & M & $\mathrm{D}$ & 14 & $0 \cdot 511$ \\
\hline Swallow/swallow bug & Shields and Crook (1987) & $\mathrm{S}$ & $\mathrm{D}$ & 4 & $0 \cdot 96$ \\
\hline Red colobus monkey/endoparasite & Snaith et al. (2008) & M & I & 9 & -0.934 \\
\hline Black howler monkey/endoparasite & Trejo-Macías et al. (2007) & M & I & 8 & $0 \cdot 645$ \\
\hline
\end{tabular}

prevalence and host mobility. Côté and Poulin (1995) did not incorporate studies of parasite species richness, nor did they consider differences in direct and indirect parasite transmission modes in their analyses. Rifkin et al. (2012) did evaluate the effect of group size on parasite species richness and did not find any effect. Since Côté and Poulin's (1995) metaanalysis, several studies elucidating the relationship between group size and parasite infection risk have been published and meta-analytical techniques have improved. While Rifkin et al. (2012) offer a phylogenetic analysis of various measures of parasite infection and host group size, as well as taxon-specific analyses, they do not evaluate several biologically meaningful explanatory variables, such as host mobility. In this article, we re-evaluate the literature and examine the relationship between host group size and parasite infection. Since our dataset spans a broad range of taxa, life histories and evolutionary lineages, we made the following assumptions. First, we assumed that host individuals are similarly susceptible to parasitism across group sizes, which Møller (1987) showed might not always be the case. Second, we assumed an even distribution of immunity against parasites across group sizes within species (Wilson et al. 2003).

\section{MATERIALS AND METHODS}

\section{Data collection}

All data were collected from an extensive search of the literature published on or before 26 June 2012.
A complete search of ISI Web of Science, Google Scholar, BIOSIS and PubMed was performed using all possible combinations of the terms: 'parasite', 'parasitoid', 'pathogen', 'disease' and 'infection' in conjunction with 'group size', 'group', 'colony size', 'colony', 'colonial', 'gregarious', 'social' and 'communal'. References within collected published studies and all publications citing Côté and Poulin (1995) were searched for pertinent data. These sources of information should provide comprehensive coverage of the published data on this topic. To be included in the analysis, reported results had to meet several main criteria. First, studies were included in the dataset if they reported a correlation coefficient (either Pearson or Spearman) between group size and 1 of 3 different measures of parasite infection risk: prevalence, intensity or species richness. These 3 measures of infection are most often predicted to correlate with gregariousness and group size in social animals. Pearson and Spearman correlation coefficients are commonly used as measures of effect size in meta-analyses (i.e. Côté and Poulin, 1995; Gontard-Danek and Møller, 1999) and are appealing because their squared value represents the variance in the response variable explained by the predictor. Second, published data were only included if the sample size (i.e. number of groups observed) was reported. Third, we chose not to mix single species and phylogenetic studies in our analyses. For example, in Table 1 (parasite prevalence) we chose to omit studies of cross-species relationships between mean group size and mean prevalence (e.g. Gregory et al. 1991, where $n=86$ 
phylogenetically independent contrasts but is actually based on $100+$ bird species). Mixing single species and phylogenetic studies is problematic in that there are obvious potential differences between within-species and cross-species patterns and the weighting of studies is thrown into question as, for example, 86 buffalo groups (i.e. one species) would be as heavily weighted as the 86 independent contrasts from $100+$ bird species. For Table 3 (species richness), we chose to omit the one single species study (Snaith et al. 2008) since all other studies were cross-species analyses. Additionally, where data on the same host-parasite interaction were reported in the same study population across several years (e.g. Brown et al. 2001) a composite mean effect was used in the analyses so as to deal with a possible lack of independence between the data. Finally, because different taxonomic groups of hosts contributed unequally to our dataset, we included higher taxa of hosts as a moderator in the models to control for any bias due to a taxonomically unbalanced dataset.

\section{Classification of data}

The dataset was divided to test several hypotheses regarding host behaviour and parasite transmission dynamics. A separate meta-analysis was carried out to test each hypothesis where the data allowed.

Sedentary hosts. Sedentary hosts were considered as species or populations associated with a specific area for the duration of the original study, such as nests, burrows, or a highly restricted range (i.e. prairie dogs that remain on their group's territory, colonially nesting birds that remain in the colony, nests or nestlings that remain stationary).

Mobile hosts. Mobile hosts on the other hand were considered to be those species or populations that range widely or whose location was not spatially predictable during the course of the original study (i.e. most ungulates with large home ranges, freeswimming fish).

Mode of parasite transmission. We looked at directly transmitted parasites (contact-transmitted, immediately infective), indirectly transmitted parasites (most parasites that require off-host development) and mobile parasites (parasites that can freely move and actively seek new hosts, often by flying or swimming: flies, some swimming crustaceans, many microparasites and their vectors).

\section{Statistical analyses}

Meta-analysis is widely regarded as being a powerful method by which to quantitatively test hypotheses using previously published results (Cadotte et al.
2012; Nakagawa and Poulin, 2012). Meta-analysis involves weighting effect size against the sample size. This is accomplished by transforming test statistics into a common metric called the effect size, which is a 'standardized measure of the strength of a relationship between two variables of interest' (Møller and Jennions, 2001). The measures of effect size used here were obtained from Pearson and Spearman correlation coefficients drawn from the pertinent literature. Correlation coefficients were transformed by means of Fisher's transformation to $Z$ values (Sokal and Rohlf, 1995) and these $Z$ values were used as the effect size in subsequent analyses. Mixed effects models were used to analyse each of the datasets with host species entered as a moderator variable (Hunter and Schmidt, 2000). Mixed effects models are random effects models with a moderator variable, and can be preferable in ecological studies where variation in observed effects is not due solely to sampling error and effect sizes are expected to vary between taxa and ecosystems (Jennions and Møller, 2002). By allowing for random sources of variation in effect sizes between studies, as well as in sampling error, random effect models can account for random variance caused by stochastic and biological processes (Jennions and Møller, 2002). Confidence intervals $(95 \%)$ are reported and the mean effect size can be interpreted as being significantly different from zero if the $95 \%$ confidence intervals do not overlap zero. This relationship is also reflected in the $P$-values (i.e. $P<0 \cdot 05$ ).

Publication bias can be problematic for analyses that rely on previously published findings. In order to overcome the potential hurdles imposed by publication bias, several statistical methods have been developed for use in meta-analyses to both detect and adjust for any bias in the data (Møller and Jennions, 2001), although there is only one true way of testing for publication bias and that is to compare published and unpublished studies. Here, we estimated the potential for publication bias in the data by use of rank correlation tests (Begg and Mazumdar, 1994). The rank correlation test uses Spearman rank correlations to investigate the relationship between the effect size and sample size. Plotting effect size against sample size should reveal a funnel-shaped plot (funnel plot): larger variance in effect sizes when sample size is small with decreasing variance as sample size increases. If the funnel plot is significantly skewed (i.e. asymmetric) in any way, the rank correlation test will show this (i.e. $P<0 \cdot 05$ ) and appropriate measures can be taken to correct for the bias. The rank correlation test is regarded as being a fairly powerful test for investigating publication bias (Møller and Jennions, 2001). Publication bias was not detected for any of the tests in this study. We also determined fail-safe numbers for each of the metaanalyses using the Rosenthal method (Rosenthal, 1979). Fail-safe numbers represent the number of 
Table 2. Studies on the relationship between host group size and parasite intensity included in the meta-analyses

(Presented here, with number of groups examined $(n)$, the correlation coefficient $(r)$, host mobility $(\mathrm{M}=$ mobile, $\mathrm{S}=$ sedentary $)$, transmission mode $(\mathrm{I}=$ indirect, $\mathrm{D}=$ direct, $\mathrm{M}=$ mobile $)$ )

\begin{tabular}{|c|c|c|c|c|c|}
\hline Host/parasite system & Reference & $\begin{array}{l}\text { Host } \\
\text { mobility }\end{array}$ & $\begin{array}{l}\text { Transmission } \\
\text { mode }\end{array}$ & $n$ & $r$ \\
\hline Marmot/mite & Arnold and Lichtenstein (1993) & $\mathrm{S}$ & $\mathrm{D}$ & 35 & $0 \cdot 03$ \\
\hline Swallow/flea & Brown and Brown (1986) & $\mathrm{S}$ & $\mathrm{D}$ & 6 & $0 \cdot 48$ \\
\hline Swallow/swallow bug & Brown and Brown (1986) & $\mathrm{S}$ & $\mathrm{D}$ & 13 & $0 \cdot 63$ \\
\hline Swallow/arbovirus-swallow bug & Brown et al. (2001) & $\mathrm{S}$ & $\mathrm{D}$ & 30 & $0 \cdot 6$ \\
\hline Sunfish/fungus & Côté and Gross (1993) & $\mathrm{S}$ & M & 22 & $-0 \cdot 55$ \\
\hline Eland/coccidia & Ezenwa (2004) & M & I & 15 & $0 \cdot 671$ \\
\hline Eland/strongyle & Ezenwa (2004) & M & I & 15 & $0 \cdot 077$ \\
\hline Grant's gazelle/coccidia & Ezenwa (2004) & M & I & 15 & $0 \cdot 48$ \\
\hline Grant's gazelle/strongyle & Ezenwa (2004) & M & I & 15 & $0 \cdot 265$ \\
\hline Impala/coccidia & Ezenwa (2004) & M & I & 15 & $0 \cdot 2$ \\
\hline Thomson’s gazelle/coccidia & Ezenwa (2004) & M & I & 15 & 0.794 \\
\hline Thomson's gazelle/strongyle & Ezenwa (2004) & M & I & 15 & $0 \cdot 2$ \\
\hline Buffalo/coccidia & Ezenwa (2004) & M & I & 15 & $0 \cdot 52$ \\
\hline Buffalo/strongyle & Ezenwa (2004) & M & I & 15 & $0 \cdot 071$ \\
\hline Hartebeest/coccidia & Ezenwa (2004) & M & I & 15 & $0 \cdot 458$ \\
\hline Hartebeest/strongyle & Ezenwa (2004) & M & I & 15 & $0 \cdot 648$ \\
\hline Impala/strongyle & Ezenwa (2004) & M & I & 15 & $0 \cdot 089$ \\
\hline Ground squirrel/ectoparasite & Hillegass et al. (2008) & $\mathrm{S}$ & $\mathrm{D}$ & 18 & $-0 \cdot 16$ \\
\hline Ground squirrel/endoparasite & Hillegass et al. (2008) & $\mathrm{S}$ & I & 18 & $0 \cdot 14$ \\
\hline Swallow/flea & Hoogland and Sherman (1976) & $\mathrm{S}$ & $\mathrm{D}$ & 22 & $0 \cdot 75$ \\
\hline Prairie dog/flea & Hoogland (1979) & $\mathrm{S}$ & $\mathrm{D}$ & 9 & $0 \cdot 28$ \\
\hline Prairie dog/flea & Hoogland (1979) & $\mathrm{S}$ & $\mathrm{D}$ & 10 & $0 \cdot 72$ \\
\hline Badger/flea & Johnson et al. (2004) & $\mathrm{S}$ & D & 21 & $0 \cdot 413$ \\
\hline Bat/bat fly & Kunz (1976) & M & $\mathrm{D}$ & 6 & $0 \cdot 94$ \\
\hline Swallow/swallow bug & Loye and Carroll (1991) & $\mathrm{S}$ & $\mathrm{D}$ & 8 & $0 \cdot 03$ \\
\hline Stickleback/branchiuran & Poulin and Fitzgerald (1989) & M & M & 4 & $-0 \cdot 81$ \\
\hline Stickleback/branchiuran & Poulin and Fitzgerald (1989) & M & M & 4 & $-0 \cdot 72$ \\
\hline Stickleback/crustacean & Poulin (1999) & M & M & 14 & $-0 \cdot 465$ \\
\hline Stickleback/copepod & Poulin (1999) & M & $\mathrm{D}$ & 14 & $0 \cdot 706$ \\
\hline Horse/nematode & Rubenstein and Hohmann (1989) & M & I & 5 & $0 \cdot 91$ \\
\hline Horse/dipteran & Rubenstein and Hohmann (1989) & M & M & 6 & $-0 \cdot 94$ \\
\hline Horse/dipteran & Rutberg (1987) & M & M & 42 & $-0 \cdot 25$ \\
\hline French grunt/monogenean & Sasal (2003) & M & I & 4 & $0 \cdot 878$ \\
\hline Swallow/flea & Shields and Crook (1987) & $\mathrm{S}$ & $\mathrm{D}$ & 4 & $0 \cdot 86$ \\
\hline
\end{tabular}

null results needed to eliminate an effect, or to change a significant result to a non-significant one (Møller and Jennions, 2001).

Meta-analyses were carried out in $\mathrm{R}$ version 2.15.0 (R Development Core Team, 2010) using the 'metafor' package (Viechtbauer, 2010) and the 'psychometric' package (Fletcher, 2008). The 'metafor' package was used to generate the meta-analyses using maximum likelihood techniques, create funnel plots, conduct the rank correlation publication bias test, and to generate the fail-safe numbers. The 'psychometric' package was used to convert reported correlation coefficients to $Z$ values for use in the meta-analyses.

\section{RESULTS}

Seventy correlations were found that met the selection criteria. Nineteen of these reported data on parasite prevalence and group size (Table 1), 34 correlations reported data on parasite intensity and group size (Table 2) and 17 reported data on parasite species richness and group size (Table 3 ). The average sample size across all studies was $n=22 \cdot 8$ groups (range: 4-86 groups), for parasite prevalence studies the average sample size was $n=15 \cdot 8$ groups (range: 4-32 groups), for parasite intensity studies the average sample size was $n=14 \cdot 6$ groups (range: $4-42$ groups) and the average sample size for parasite species richness studies was $n=37.9$ groups (range: 8-86 groups).

\section{Relationships between host group size and parasite prevalence}

Among comparisons of parasite prevalence, the effect size estimate was high and significantly different from zero (Table $4 \mathrm{a}$ ). Thus, a strong positive correlation was found between overall parasite prevalence and group size. Similar positive correlation trends were also found between group size and both directly transmitted parasites (Table 4a) and indirectly 
Table 3. Studies on the relationship between host group size and parasite species richness included in the meta-analyses

(Presented here, with number of groups examined $(n)$, the correlation coefficient $(r)$, host mobility $(\mathrm{M}=$ mobile), transmission mode $(\mathrm{I}=$ indirect, $\mathrm{D}=$ direct, $\mathrm{M}=$ mobile $)$ )

\begin{tabular}{|c|c|c|c|c|c|}
\hline Host/parasite system & Reference & $\begin{array}{l}\text { Host } \\
\text { mobility }\end{array}$ & $\begin{array}{l}\text { Transmission } \\
\text { mode }\end{array}$ & $n$ & $r$ \\
\hline Hoofed mammal/arthropod & Ezenwa et al. (2006) & M & $\mathrm{D}$ & 64 & $-0 \cdot 32$ \\
\hline Hoofed mammal/helminth & Ezenwa et al. (2006) & M & I & 64 & $-0 \cdot 33$ \\
\hline Hoofed mammal/microparasite & Ezenwa et al. (2006) & M & - & 64 & $-0 \cdot 08$ \\
\hline Primate/protozoan & Freeland (1979) & M & I & 11 & $0 \cdot 91$ \\
\hline Birds/cestode & Gregory et al. (1991) & M & I & 86 & $-0 \cdot 1$ \\
\hline Birds/nematode & Gregory et al. (1991) & M & I & 84 & $0 \cdot 2$ \\
\hline Birds/trematode & Gregory et al. (1991) & M & I & 83 & $-0 \cdot 06$ \\
\hline Teleost fish/metazoan & Luque et al. (2004) & M & - & 8 & $0 \cdot 0491$ \\
\hline Cyprinidae/ectoparasites & Poulin $(1991 a)$ & M & $\mathrm{D}$ & 33 & $-0 \cdot 21$ \\
\hline Cyprinidae/endoparasites & Poulin (1991a) & M & I & 33 & 0.062 \\
\hline Percidae/ectoparasites & Poulin (1991a) & M & $\mathrm{D}$ & 10 & $-0 \cdot 174$ \\
\hline Percidae/endoparasites & Poulin (1991a) & M & I & 10 & $0 \cdot 77$ \\
\hline Salmonoid/ectoparasites & Poulin $(1991 a)$ & M & $\mathrm{D}$ & 17 & $0 \cdot 455$ \\
\hline Salmonoid/endoparasites & Poulin (1991a) & M & I & 17 & $0 \cdot 435$ \\
\hline Cyprinidae/mobile parasites & Poulin (1991a) & M & M & 33 & $-0 \cdot 106$ \\
\hline Percidae/mobile parasites & Poulin $(1991 a)$ & M & M & 10 & $-0 \cdot 073$ \\
\hline Salmonoid/mobile parasites & Poulin (1991a) & M & M & 17 & $0 \cdot 314$ \\
\hline
\end{tabular}

Table 4. Results from each separate meta-analysis regarding parasite infection in group-living species

(With number of studies $(n)$, overall mean correlation coefficient (Mean $r$ ), $95 \%$ confidence intervals, $Z$ score, $P$-value of significance test and fail-safe numbers)

\begin{tabular}{|c|c|c|c|c|c|c|}
\hline & $n$ & Mean $r$ & $95 \% \mathrm{CI}$ & $Z$ & $P$ & Fail-safe \\
\hline (a) Parasite prevalence & 19 & $0 \cdot 500$ & $0 \cdot 049,0 \cdot 114$ & $4 \cdot 950$ & $<0 \cdot 0001$ & 104 \\
\hline Directly transmitted parasites & 6 & $0 \cdot 770$ & $0 \cdot 116,0 \cdot 382$ & $3 \cdot 669$ & $0 \cdot 0002$ & 28 \\
\hline Indirectly transmitted parasites & 13 & $0 \cdot 369$ & $0 \cdot 033,0 \cdot 130$ & $3 \cdot 269$ & $0 \cdot 0011$ & 15 \\
\hline (b) Parasite intensity & 34 & $0 \cdot 331$ & $0 \cdot 013,0 \cdot 048$ & $3 \cdot 376$ & $0 \cdot 0007$ & 105 \\
\hline Mobile parasites & 6 & $-0 \cdot 540$ & $-0 \cdot 107,-0 \cdot 009$ & $-2 \cdot 322$ & $0 \cdot 0202$ & 13 \\
\hline Directly transmitted parasites & 13 & $0 \cdot 550$ & $0 \cdot 017,0 \cdot 066$ & $3 \cdot 369$ & $0 \cdot 0008$ & 54 \\
\hline Indirectly transmitted parasites & 15 & $0 \cdot 424$ & $0 \cdot 017,0 \cdot 078$ & $3 \cdot 031$ & $0 \cdot 0024$ & 49 \\
\hline Mobile host & 21 & $0 \cdot 225$ & $-0 \cdot 001,0 \cdot 054$ & $1 \cdot 886$ & $0 \cdot 059$ & 23 \\
\hline Sedentary host & 13 & $0 \cdot 325$ & $0 \cdot 010,0.059$ & $2 \cdot 742$ & $<0.0099$ & 14 \\
\hline (c) Parasite species richness & 17 & $0 \cdot 070$ & $-0 \cdot 023,0 \cdot 078$ & $1 \cdot 066$ & $0 \cdot 287$ & 0 \\
\hline Directly transmitted parasites & 4 & -0.099 & $-0 \cdot 175,0 \cdot 193$ & $0 \cdot 097$ & 0.923 & 0 \\
\hline Indirectly transmitted parasites & 8 & $0 \cdot 212$ & $-0 \cdot 026,0 \cdot 090$ & $1 \cdot 085$ & $0 \cdot 278$ & 0 \\
\hline
\end{tabular}

transmitted parasites (Table 4a). No studies were found that reported data on group size and parasite prevalence for mobile parasites (Table 1). Due to high co-variation between studies on mode of transmission and host mobility, we did not test for effects of host mobility on parasite prevalence.

\section{Relationships between host group size and parasite intensity}

Larger groups had more intense parasite infections than expected by chance (Table 4b). The intensities of directly transmitted parasites (Table 4b) and indirectly transmitted parasites (Table 4b) also showed significant positive trends with increasing group size (Table 4b). The relationship between mobile parasite intensity and group size showed a significant negative trend (Table 4b). Host mobility played a role in determining parasite infection intensity, with larger groups of sedentary hosts more likely to have higher parasite intensities (Table 4b). Mobile hosts did not show a significant effect of group size and parasite intensity (Table 4b).

\section{Relationships between host group size and parasite species richness}

Finally, for overall parasite species richness the effect size was low, making it likely that the observed mean could have been obtained by chance (Table $4 \mathrm{c}$ ). 
No trend was obtained for the relationship between directly or indirectly transmitted parasite species richness and group size (Table 4c). All available studies were from mobile hosts so distinctions between mobile and sedentary hosts could not be made (Table 1).

\section{DISCUSSION}

\section{Parasite prevalence and intensity}

We have noted general trends spanning a variety of taxa that support a positive relationship between group sizes in social animals and the infection intensity and prevalence of many parasites. These findings are consistent with previous meta-analyses (Côté and Poulin, 1995; Rifkin et al. 2012). This result is not surprising when we consider that all contagious (i.e. non-mobile) parasites require direct contact between susceptible hosts and infective stages and that most parasites exhibit density-dependent or frequency-dependent transmission. Accordingly, the results presented here are supported by predictions of epidemiological models and social evolution theory (Alexander, 1974; Anderson and May, 1978). Epidemiological models predict that parasite transmission will be enhanced in group-living species due to increased proximity and contact with infective stages (Anderson and May, 1978) resulting in elevated parasite infections amongst group members. As such, increased parasite infection intensity and prevalence appear to be costs of group-living across a broad range of host and parasite species. Where the costs of parasitism are great, parasites may thus put constraints on optimal group sizes and the evolutionary stability of social groups.

In contrast, we have also shown here that forming groups may be beneficial to individuals faced with infection by mobile parasites (i.e. dipterans, mosquitoes), possibly through the encounter-dilution effect. When confronted with mobile parasites, group formation is predicted to reduce the attack rate per individual group member (Freeland, 1977). To date, no studies have been conducted to test the relationship between group size and the prevalence of mobile parasites. Studies of mobile parasite intensity are more common and there is good support for a dilution effect (grouping benefits) when mobile parasites are present. For instance, Poulin and Fitzgerald (1989) experimented with a mobile crustacean ectoparasite that parasitizes stickleback fish and found that attack rates increased less than linearly so that each individual in the group was less at risk when in a larger group. In mammals, Freeland (1977), Duncan and Vigne (1979), Espmark and Langvatn (1979), Rutberg (1987) and Rubenstein and Hohmann (1989) have all found positive effects of grouping through reduced attack rates of mobile parasites. The results presented here are in agreement with Côté and Poulin (1995) in terms of the overall trend observed between group size and mobile parasite intensity, but differ from those of Rifkin et al. (2012), possibly owing to differences in analytical techniques.

Interestingly, the mobility of the host appears to be important. Mobile hosts are able to move away from infected areas or hosts and this ability to escape may mitigate the effect of group size on parasite infection intensity. Mobile hosts may also have less rigid group structures than sedentary hosts, which may lead to highly variable group sizes over time and may confound studies looking for group size effects. Additionally, larger, less stable groups have been shown to experience increased social stress related to crowding and/or less rigid dominance hierarchies (Sapolsky, 2005). The majority (15 of 21) of the group-living species included in the mobile hostparasite intensity meta-analysis presented here are species that exhibit some form of hierarchical social structure. Dominant individuals generally have higher levels of androgen hormones (i.e. testosterone), which are known to suppress host immune function (Sapolsky, 2005; Nunn et al. 2009). Additionally, dominant individuals that frequently engage in physical combat to maintain rank may be more likely to acquire directly (contact) transmitted parasites. Submissive individuals typically have higher levels of cortisol, a stress hormone that has also been linked to a reduced immune function (Gulland, 1992). Subordinates may also have fewer possibilities to select grazing locations and may incur a higher risk of parasitism by grazing in less preferred, contaminated locations (Hutchings et al. 2002). As a result, group-living animals that form dominance hierarchies may experience variable or skewed parasite intensities depending on the social system and physiological responses of the species or population, which could not be addressed in our study.

In sedentary groups, the social contact networks and transmission patterns are spatially and temporally stable, which may foster continual transmission of parasites between neighbours. Most studies of sedentary hosts consider nesting or burrowing species. Nests and burrows are spatially fixed features that hosts are 'attached' to, at least for the duration of study. For instance, prairie dogs typically hold the same burrow location throughout their lifetime and interact with the same set of neighbours most frequently (Hoogland, 1995). Transmission of parasites is likely then facilitated by repeated interactions between neighbours and by continuous host exposure to infective stages, such that parasites are readily shared between adjacent and nearby hosts. In some cases, neighbours are kin and related hosts may have common genetic dispositions to infection (i.e. weak immune systems). As such, we should expect that patterns of parasite infection 
intensity would hold for sedentary hosts, and indeed we find that they do.

If hosts are faced with a virulent parasite and higher contact rates induce greater parasite transmission, evolutionary forces should drive the host to respond with lower rates of contact to a point where the costs of group-living are minimized. Bonds et al. (2005) point out the conspicuous absence of published studies that have found a negative correlation between group size and contagious parasite prevalence. This is substantiated here as we could only find 1 study that reported a negative relationship between group size and prevalence that met the selection criteria. Bonds et al. (2005) question that if animal behaviours change in response to infection risk, why is it that we have not seen evidence of more substantial evolutionary influences on social structure? It is clear that the evolutionary relationship between hosts and parasites is not unidirectional, and that parasites should be expected to evolve mechanisms to overcome host adaptations and vice versa (i.e. Hamilton et al. 1990; Webster et al. 2004; Decaestecker et al. 2007; Duffy and Sivars-Becker, 2007; Morran et al. 2011). Importantly, the evolutionary history and the fitness costs of infection should be explicitly stated in all studies of hostparasite interactions. Host specificity of the parasite also needs to be taken into consideration. Studies have shown that parasite species able to exploit many taxonomically unrelated hosts often achieve higher intensities than specialist parasites, possibly because host species have developed particular defences for coping with specialist parasites, but not generalists (Krasnov et al. 2004). Ezenwa (2004) showed that gregarious species were more likely to be infected than were solitary species with generalist species of strongyles (a gastrointestinal parasite). For strongyles, contact with heterospecifics and conspecifics could both affect the rates of exposure to this group of parasites (Ezenwa, 2004). Finally, intersexual differences may drive the parasite transmission dynamics, but often sex ratios are not explicitly considered in studies of group size. Sex ratios can be extremely biased in many groups, such as harems and sexually segregated groups. In studies of group-living species it is pertinent to acknowledge that males and females are often not infected by parasites in the same manner and the transmission dynamics and infection risk can be affected by the sex ratio. In most vertebrate species, males are more likely to be infected with parasites (higher prevalence) and carry a higher intensity of infection than are females of the same species (Poulin, 1996; Zuk and McKean, 1996; Schalk and Forbes, 1997; Moore and Wilson, 2002; Ferrari et al. 2004; Klein, 2004; Hillegass et al. 2008). Therefore, groups with male-biased sex ratios may be at an elevated risk of acquiring parasites and maintaining infections. One hypothesis that is especially pertinent to group-living species, but which has received very little attention to date, is that males and females may sexually segregate as a means to avoid parasite transmission (Ferrari et al. 2010).

\section{Parasite species richness}

Hosts with higher mobility or those that live in open societies with intergroup member exchange are widely hypothesized to have higher parasite species richness because contact with a diversity of individuals and environments should promote the acquisition of novel parasites. A large group is also more likely to contain a group member (or members) with rare parasite fauna. Freeland (1979) found more protozoan species in larger mangabey (Cercocebus albigena) and blue monkey (Cercopithecus mitis) groups inhabiting the same area. However, results from subsequent studies testing associations between group size or group-living and parasite species richness have varied considerably, with some studies showing positive relationships, some showing negative relationships, and others showing no relationship at all (Gregory et al. 1991; Poulin, 1991a, 1991b; Ranta, 1992; Watve and Sukumar, 1995; Tripet et al. 2002; Nunn et al. 2003; Vitone et al. 2004). The results presented here support the conclusion that no broad general trends between parasite species richness and group size appear to exist in the available literature, counter to our original prediction. These findings are in concordance with Rifkin et al. (2012). Given the complexities of host social behaviour, it is likely that the degree and directionality of the effect of host group size on parasite species richness depends on the specific social system of the host group/species under consideration and on other elements of host behaviour that affect contact rates, such as dominance hierarchies (Wilson et al. 2003).

Some authors have argued that sociality should lower the risk of parasite transmission if increased clustering of individuals into relatively permanent groups effectively quarantines parasites into discrete host patches (Hess, 1996; Watve and Jog, 1997; Wilson et al. 2003). Freeland (1979) proposed that individuals that remain within a group are less likely to become infected with parasites to which they have not previously been exposed than are individuals that frequently engage in extra-group social relationships. In this sense, closed social groups or more sedentary groups may act as barriers to parasite transmission between groups or extra-group members (Loehle, 1995), leading to reduced species richness.

\section{CONCLUSIONS}

Sociality is thought to be one of the last major evolutionary transitions (Jackson and Hart, 2009) and group-living generates many advantages, such as diluted predation risk, extended parental care and 
enhanced potential for information sharing (Krause and Ruxton, 2002). However, group-living also imposes costs, particularly a predicted increase in the risk of parasite infection. Local population density and social group size can increase rates of host-host contact and host interaction with parasiteinfective stages. While the role of parasites in the evolution of group formation and sociality are far from clear, empirical evidence appears to support the hypothesis that parasites can exert selective pressures on group size and group formation, and may have driven, at least in part, the evolution of social behaviours. We have shown here that parasite intensity and parasite prevalence generally trend positively with increasing group size, suggesting an increased cost associated with forming larger groups.

The results presented here are correlational and do not allow explicit derivations of causative mechanisms. Future research should focus on the causes of increased parasite intensity and prevalence in groups and the selective forces imposed by parasites on group formation and stability. In order to fully assess these problems, the costs of parasitism must be explicitly determined a priori. If parasites do not impose appreciable costs on host fitness (i.e. reduced offspring growth and survival, reduced mating success, reduced lifespan), then parasitism should not be expected to function as an evolutionary pressure influencing group size. It is apparent that many parasites do impose costs on the fitness of their hosts and, in this regard, parasites may constrain group size. In extreme situations, intense parasitism could lead to a reduction of social behaviour or the elimination of group-living altogether; however, the latter situation is highly unlikely. In order for groupliving to be evolutionarily stable and persistent the costs of living in groups must not outweigh the benefits. When the risk of parasite transmission increases, the costs to group-living also increase. Clearly, in these cases, benefits of group formation must be great. According to Brown and Brown (1986), '... without compensating benefits of coloniality, the cost of ectoparasitism would quickly select for solitary nesting in Cliff Swallows'.

Here we see that parasitism can be one of the most important costs associated with sociality and groupliving. However, in the case of mobile parasites, group-living appears to be beneficial for reducing parasite intensities. Therefore, when grouping leads to increased parasite infection, group size will be down-regulated to achieve an optimal group size that balances the costs of parasitism with the other benefits of group-living. However, in cases where grouping reduces parasite attack rates, lower parasitism will be a benefit of group-living and group sizes may be larger than expected.

Ultimately, group-living has probably evolved several times and for several different reasons (Alexander, 1974), so parasite infection must be considered along with other factors that favour or discourage gregariousness, such as predation and competition, in a complete cost-benefit model. If we are to fully understand why animals live in groups we must employ a holistic approach that incorporates multiple explanatory factors, in particular hostparasite phylogenies, host sex, host group structure, parasite specificity and parasite transmission mode, in comparative analyses that will allow us to examine the links between host sociality and parasite infection in a broader context. Even after over 15 years of intense study, it is still necessary to echo Côté and Poulin's (1995) call for future studies that focus on experimental manipulations of parasite infection risk in gregarious species in order to elucidate the causative factors modulating optimal group sizes in free-ranging animals. Additionally, studies on the relationship between parasite prevalence and group size are needed specifically for sedentary species and indirectly transmitted parasites.

\section{ACKNOWLEDGEMENTS}

We are grateful to R. M. R. Barclay, S. Kutz, M. Pavelka, $\mathrm{M}$. Jennions and one anonymous reviewer for thoughtful discussion and critique.

\section{FINANCIAL SUPPORT}

An NSERC Canada Graduate Scholarship, Bettina Bahlsen Memorial Scholarship, and Queen Elizabeth II Scholarship supported J.E.H.P.

\section{REFERENCES}

Alexander, R. D. (1974). The evolution of social behavior. Annual Review of Ecology and Systematics 5, 325-383.

Altizer, S., Nunn, C. L., Thrall, P. H., Gittleman, J. L., Antonovics, J., Cunningham, A. A., Dobson, A.P., Ezenwa, V., Jones, K. E., Pedersen, A. B., Poss, M. and Pulliam, J. R. C. (2003). Social organization and parasite risk in mammals: integrating theory and empirical studies. Annual Review of Ecology, Evolution and Systematics 34, 517-547.

Anderson, R. M. and May, R. M. (1978). Regulation and stability of host-parasite population interactions: I. regulatory processes. Fournal of Animal Ecology 47, 219-247.

Arnold, W. and Lichtenstein, A. V. (1993). Ectoparasite loads decrease the fitness of alpine marmots (Marmota marmota) but are not a cost of sociality. Behavioral Ecology 4, 36-39.

Begg, C. B. and Mazumdar, M. (1994). Operating characteristics of a rank correlation test for publication bias. Biometrics 50, 1088-1101.

Bonds, M. H., Keenan, D. C., Leidner, A. J. and Rohani, P. (2005). Higher disease prevalence can induce greater sociality: a game theoretic coevolutionary model. Evolution 59, 1859-1866.

Brown, C. R. and Brown, M. B. (1986). Ectoparasitism as a cost of coloniality in cliff swallows (Hirundo pyrrhonota). Ecology 67, 1206-1218.

Brown, C. R., Komar, N., Quick, S. B., Sethi, R. A., Panella, N. A., Brown, M. B. and Pfeffer, M. (2001). Arbovirus infection increases with group size. Proceedings of the Royal Society of London. Series B: Biological Sciences 268, 1833-1840.

Bush, A. O., Lafferty, K. D., Lotz, J. M. and Shostak, A. W. (1997). Parasitology meets ecology on its own terms: Margolis et al. revisited. Fournal of Parasitology 83, 575-583.

Cadotte, M., Mehrkens, L. and Menge, D. L. (2012). Gauging the impact of meta-analysis on ecology. Evolutionary Ecology 26, 1153-1167.

Cappuccino, N. (1988). Spatial patterns of goldenrod aphids and the response of enemies to patch density. Oecologia 76, 607-610.

Côté, I. M. and Gross, M. R. (1993). Reduced disease in offspring: a benefit of coloniality in sunfish. Behavioral Ecology and Sociobiology 33, 269-274. 
Côté, I. M. and Poulin, R. (1995). Parasitism and group size in social animals: a meta-analysis. Behavioral Ecology 6, 159-165.

Decaestecker, E., Gaba, S., Raeymaekers, J. A. M., Stoks, R., Van Kerckhoven, L., Ebert, D. and De Meester, L. (2007). Host-parasite 'Red Queen' dynamics archived in pond sediment. Nature 450, 870-873.

Duffy, M. A. and Sivars-Becker, L. (2007). Rapid evolution and ecological host-parasite dynamics. Ecology Letters 10, 44-53.

Duncan, P. and Vigne, N. (1979). The effect of group size in horses on the rate of attacks by blood-sucking flies. Animal Behaviour 27, 623-625.

Espmark, Y. and Langvatn, R. (1979). Lying down as a means of reducing fly harassment in red deer (Cervus elaphus). Behavioral Ecology and Sociobiology 5, 51-54.

Ezenwa, V. O. (2004). Host social behavior and parasitic infection: a multifactorial approach. Behavioral Ecology 15, 446-454.

Ezenwa, V. O., Price, S. A., Altizer, S., Vitone, N. D. and Cook, K. C. (2006). Host traits and parasite species richness in even and odd-toed hoofed mammals, Artiodactyla and Perissodactyla. Oikos 115, 526-536.

Ferrari, N., Cattadori, I. M., Nespereira, J., Rizzoli, A. and Hudson, P. J. (2004). The role of host sex in parasite dynamics: field experiments on the yellow-necked mouse Apodemus flavicollis. Ecology Letters 7, 88-94

Ferrari, N., Rosa, R., Lanfranchi, P. and Ruckstuhl, K. E. (2010). Effect of sexual segregation on host-parasite interaction: model simulation for abomasal parasite dynamics in alpine ibex (Capra ibex). International Fournal for Parasitology 40, 1285-1293.

Fletcher, T.D. (2008). Psychometric: applied psychometric theory. In $R$ package version 2.0. Available from cran.r-project.org/web/packages/ psychometric/index.html

Freeland, W. J. (1977). Blood-sucking flies and primate polyspecific associations. Nature, London 269, 801-802.

Freeland, W. J. (1979). Primate social groups as biological islands. Ecology 60, 719-728.

Gontard-Danek, M. C. and Møller, A. P. (1999). The strength of sexua selection: a meta-analysis of bird studies. Behavioral Ecology 10, 476-486. Gregory, R. D., Keymer, A. E. and Harvey, P. H. (1991). Life history, ecology and parasite community structure in Soviet birds. Biological fournal of the Linnean Society 43, 249-262.

Gulland, F. M. D. (1992). The role of nematode parasites in Soay sheep (Ovis aries L.) mortality during a population crash. Parasitology 105, 493-503.

Hamilton, W. and Zuk, M. (1982). Heritable true fitness and bright birds: a role for parasites? Science 218, 384-387.

Hamilton, W. D., Axelrod, R. and Tanese, R. (1990). Sexual reproduction as an adaptation to resist parasites (a review). Proceedings of the National Academy of Sciences USA 87, 3566-3573.

Hess, G. (1996). Disease in metapopulation models: implications for conservation. Ecology 77, 1617-1632.

Hillegass, M. A., Waterman, J. M. and Roth, J. D. (2008). The influence of sex and sociality on parasite loads in an African ground squirrel. Behavioral Ecology 19, 1006-1011.

Hoogland, J. L. (1979). Aggression, ectoparasitism, and other possible costs of prairie dog (Sciuridae, Cynomys spp.) coloniality. Behaviour 69, 1-35.

Hoogland, J. L. (1995). The Black-Tailed Prairie Dog: Social life of a Burrowing Animal. University of Chicago Press, Chicago, IL, USA.

Hoogland, J. L. and Sherman, P.W. (1976). Advantages and disadvantages of bank swallow (Riparia riparia) coloniality. Ecological Monographs 46, 33-58.

Hunter, J. E. and Schmidt, F. L. (2000). Fixed effects vs. random effect meta-analysis models: implications for cumulative research knowledge. International Yournal of Selection and Assessment 8, 275-292.

Hutchings, M. R., Milner, J. M., Gordon, I. J., Kyriazakis, I. and Jackson, F. (2002). Grazing decisions of Soay sheep, Ovis aries, on St Kilda: a consequence of parasite distribution? Oikos 96, 235-244.

Jackson, D. E. and Hart, A. G. (2009). Does sanitation facilitate sociality? Animal Behaviour 77, 1-5.

Jennions, M. D. and Møller, A. P. (2002). Publication bias in ecology and evolution: an empirical assessment using the 'trim and fill' method. Biological Reviews 77, 211-222.

Johnson, D. D. P., Stopka, P. and Macdonald, D. W. (2004). Ideal flea constraints on group living: unwanted public goods and the emergence of cooperation. Behavioral Ecology 15, 181-186.

Klein, S. L. (2004). Hormonal and immunological mechanisms mediating sex differences in parasite infection. Parasite Immunology 26, 247-264. Krasnov, B. R., Poulin, R., Shenbrot, G. I., Mouillot, D. and Khokhlova, I. S. (2004). Ectoparasitic 'jacks-of-all-trades' relationship between abundance and host specificity in fleas (Siphonaptera) parasitic on small mammals. American Naturalist 164, 506-516.
Krause, J. and Ruxton, G. D. (2002). Living in Groups. Oxford University Press, Oxford, UK.

Kunz, T. H. (1976). Observations on the winter ecology of the bat fly Trichobius corynorhini Cockerell (Diptera: Streblidae). Fournal of Medical Entomology 12, 631-636.

Loehle, C. (1995). Social barriers to pathogen transmission in wild animal populations. Ecology 76, 326-335.

Loye, J. E. and Carroll, S.P. (1991). Nest ectoparasite abundance and cliff swallow colony site selection, nestling development, and departure time. In Bird-parasite Interactions: Ecology, Evolution, and Behaviour (ed. Loye, J. E. and Zuk, M.), pp. 222-241. Oxford University Press, Oxford, UK.

Luque, J. L., Mouillot, D. and Poulin, R. (2004). Parasite biodiversity and its determinants in coastal marine teleost fishes of Brazil. Parasitology 128, 671-682.

Møller, A. P. (1987). Advantages and disadvantages of coloniality in the swallow, Hirundo rustica. Animal Behaviour 35, 819-832.

Møller, A.P. and Jennions, M. D. (2001). Testing and adjusting for publication bias. Trends in Ecology and Evolution 16, 580-586.

Moore, S. L. and Wilson, K. (2002). Parasites as a viability cost of sexual selection in natural populations of mammals. Science 297, 2015-2018.

Morran, L. T., Schmidt, O. G., Gelarden, I. A., Parrish, R. C. and Lively, C. M. (2011). Running with the Red Queen: host-parasite coevolution selects for biparental sex. Science 333, 216-218.

Nakagawa, S. and Poulin, R. (2012). Meta-analytic insights into evolutionary ecology: an introduction and synthesis. Evolutionary Ecology 26, 1085-1099.

Neuhaus, P. (2003). Parasite removal and its impact on litter size and body condition in Columbian ground squirrels (Spermophilus columbianus). Biology Letters 270, 213-215.

Nunn, C. L., Altizer, S., Jones, K. E. and Sechrest, W. (2003). Comparative tests of parasite species richness in primates. American Naturalist 162, 597-614.

Nunn, C. L., Lindenfors, P., Pursall, E. R. and Rolff, J. (2009). On sexual dimorphism in immune function. Philosophical Transactions of the Royal Society of London. Series B: Biological Sciences 364, 61-69.

Ostfeld, R. and Keesing, F. (2000). The function of biodiversity in the ecology of vector-borne zoonotic diseases. Canadian Fournal of Zoology 78, 2061-2078.

Poulin, R. (1991a). Group-living and the richness of the parasite fauna in Canadian freshwater fishes. Oecologia 86, 390-394.

Poulin, R. (1991b). Group-living and infestation by ectoparasites in passerines. Condor 93, 418-423.

Poulin, R. (1992). Altered behaviour in parasitized bumblebees: parasite manipulation or adaptive suicide? Animal Behaviour 44, 174-176.

Poulin, R. (1996). Helminth growth in vertebrate hosts: does host sex matter? International fournal for Parasitology 26, 1311-1315.

Poulin, R. (1999). Parasitism and shoal size in juvenile sticklebacks: conflicting selection pressures from different ectoparasites? Ethology 105, 959-968.

Poulin, R. and Fitzgerald, G. J. (1989). Shoaling as an anti-ectoparasite mechanism in juvenile sticklebacks (Gasterosteus spp.). Behavioral Ecology and Sociobiology 24, 251-255.

R Development Core Team (2010). R: A Language and Environment for Statistical Computing. R Development Core Team, Vienna, Austria.

Ranta, E. (1992). Gregariousness versus solitude: another look at parasite faunal richness in Canadian freshwater fishes. Oecologia 89, 150-152.

Rifkin, J. L., Nunn, C. L. and Garamszegi, L.Z. (2012). Do animals living in larger groups experience greater parasitism? A meta-analysis. American Naturalist 180, 70-82.

Rosenthal, R. (1979). The file drawer problem and tolerance for null results. Psychological Bulletin 86, 638-641

Rubenstein, D. I. and Hohmann, M. E. (1989). Parasites and social behavior of island feral horses. Oikos 55, 312-320.

Rutberg, A. T. (1987). Horse fly harassment and the social behavior of feral ponies. Ethology 75, 145-154.

Sapolsky, R. M. (2005). The influence of social hierarchy on primate health. Science 308, 648-652.

Sasal, P. (2003). Experimental test of the influence of the size of shoals and density of fish on parasite infections. Coral Reefs 22, 241-246.

Schalk, G. and Forbes, M. R. (1997). Male biases in parasitism of mammals: effects of study type, host age, and parasite taxon. Oikos $\mathbf{7 8}$, $67-74$.

Shields, W. M. and Crook, J. R. (1987). Barn swallow coloniality: a net cost for group breeding in the Adirondacks? Ecology 68, 1373-1386. Snaith, T. V., Chapman, C. A., Rothman, J. M. and Wasserman, M. D. (2008). Bigger groups have fewer parasites and similar cortisol 
levels: a multi-group analysis in red colobus monkeys. American fournal of Primatology 70, 1072-1080.

Sokal, R. and Rohlf, F. (1995). Biometry, 3rd Edn. W.H. Freeman \& Company, New York, NY, USA.

Trejo-Macías, G., Estrada, A. and Mosqueda Cabrera, M. (2007). Survey of helminth parasites in populations of Alouatta palliata mexicana and A. pigra in continuous and in fragmented habitat in southern Mexico. International Fournal of Primatology 28, 931-945.

Tripet, F., Christe, P. and Møller, A. P. (2002). The importance of host spatial distribution for parasite specialization and speciation: a comparative study of bird fleas (Siphonaptera: Ceratophyllidae). Fournal of Animal Ecology 71, 735-748.

van Baalen, M. (2002). Contact networks and the evolution of virulence. In Adaptive Dynamics of Infectious Diseases: In Pursuit of Virulence Management (ed. Dieckmann, U., Metz, J.A. J., Sabelis, M. W. and Sigmund, K.), pp. 85-103. Cambridge University Press, Cambridge, UK. Viechtbauer, W. (2010). Conducting meta-analyses in R with the metafor package. Fournal of Statistical Software 36, 1-48.
Vitone, N. D., Altizer, S. and Nunn, C. L. (2004). Body size, diet and sociality influence the species richness of parasitic worms in anthropoid primates. Evolutionary Ecology Research 6, 183-199.

Walter, D. E. and Proctor, H. C. (1999). Mites: Ecology, Evolution, and Behaviour. University of New South Wales Press, Sydney, Australia.

Watve, M. G. and Jog, M. M. (1997). Epidemic diseases and host clustering: an optimum cluster size ensures maximum survival. Fournal of Theoretical Biology 184, 167-171.

Watve, M. G. and Sukumar, R. (1995). Parasite abundance and diversity in mammals: correlates with host ecology. Proceedings of the National Academy of Sciences USA 92, 8945-8949.

Webster, J.P., Gower, C. M. and Blair, L. (2004). Do hosts and parasites coevolve? Empirical support from the Schistosoma system. American Naturalist 164, S33-S51.

Wilson, K., Knell, R., Boots, M. and Koch-Osborne, J. (2003). Group living and investment in immune defence: an interspecific analysis. Fournal of Animal Ecology 72, 133-143.

Zuk, M. and McKean, K. A. (1996). Sex differences in parasite infections: patterns and processes. International fournal for Parasitology 26, 1009-1023. 